\title{
REPORTAGEM HISTÓRICA COMO PROCEDIMENTO NARRATIVO
}

\author{
Juremir Machado da Silva
}

\begin{abstract}
RESUMO
Este texto aborda o cruzamento de história, jornalismo e literatura como procedimento para a constituição de uma narrativa específica, a grande reportagem histórica ou intelectual de aprofundamento. Explora-se uma questão simples: e se o historiador for um jornalista que cobre o passado e o narra como um escritor?
\end{abstract}

PaLAVRas-chave

Literatura; história; jornalismo; narrativa

\section{HistoricAl REPORT AS NARRATIVE PROCEDURE}

\begin{abstract}
This text approaches the intersection of history, journalism and literature as a procedure for the constitution of a specific narrative, the great historical or intellectual report of deepening. A simple question is explored: what if the historian is a journalist who covers the past and narrates him as a writer?
\end{abstract}

\section{ESCRITOR, JORNALISTA, HISTORIADOR}

Quando tudo é narrativa, expressão máxima de uma relatividade incontornável, resta decidir como narrar. Essa escolha arranca aquilo que será narrado da sua condição de massa amorfa de dados. Um aspecto sempre determinante é o ponto de vista como lugar de onde se fala: vista de um ponto. Mas que pode ser também simplesmente quem fala. Esse sujeito do discurso é em si um lugar privilegiado de fala. Um autor pode transferir a um personagem essa posição de enunciação. Mas pode também se situar como o próprio falante. De onde narrar a vida de um personagem histórico: de um ponto de vista externo ou de dentro da sua cabeça? Como narrar o momento em que Getúlio Vargas decide puxar o gatilho do seu pequeno revólver às 8 h35 de 24 de agosto de 1954?

O cruzamento num mesmo procedimento autoral das técnicas de um escritor com sua bagagem de historiador e seu imaginário de jornalista é capaz de produzir uma especificidade narrativa? Num arroubo conceitual seria possível sustentar que biografias, romances de não ficção, etnografias antropológicas, pesquisas de campo de todos 
os tipos e descrições históricas são sempre grandes reportagens. Todas baseadas nos mesmos princípios: levantar dados, reconstruir épocas e indivíduos ou observar acontecimentos e recuperar todos os lados envolvidos. Em qualquer caso, sob qualquer pretexto, trata-se de tentar descobrir o que está encoberto, fazer emergir o oculto, dar à luz, desvelar, revelar, esclarecer, focalizar, destapar, iluminar.

Cada campo de conhecimento evidentemente ergue cercas para proteger seus domínios e preservar suas propriedades duramente conquistadas. Pierre Bourdieu (1997, p. 57) escancara seu realismo.

Um campo é um espaço social estruturado, um campo de forças - há dominantes e dominados, há relações constantes, permanentes, de desigualdade, que se exercem no interior desse espaço - que é também um campo de lutas para transformar ou conservar esse campo de forças. Cada um, no interior desse universo, empenha em sua concorrência com os outros a força (relativa) que detém e que define sua posição no campo e, em consequência, suas estratégias.

Essa definição é objeto frequente de dissecação. Vale salientar que enfatiza o conflito, o jogo de interesses, o fechamento, a correlação de forças e a racionalidade das estratégias adotadas. Fica subentendido que há mobilidade dentro do campo. Para que definir estratégias se não há possibilidade de vitória? O dominante pode virar dominado, que pode se tornar dominante. A heresia vira cânone. O canônico sofre a corrosão do tempo e do novo. Cada época, porém, produz as suas condições de canonização e seus eleitos. O campo literário (Bourdieu, 1992) não é diferente. Distribui prêmios, troféus, medalhas, certificados e condecorações. Legitima e deslegitima obras e autores conforme a subjetividade objetivada dos "donos" da área em determinado tempo. Cruzar literatura, história e jornalismo significa entrar em conflito com os dominantes de três campos distintos. Pode ser uma boa estratégia narrativa, mas não se revela à primeira vista uma razoável estratégia de legitimação.

Um olhar pragmático sobre a legitimação no campo literário indica que existem dois caminhos principais: a aceitação pela crítica ou a aceitação pelo público. Vender pouco, mas ser admirado pelos "formadores de opinião", ou vender muito e se impor como um autor de mercado. O cruzamento dos dois é infrequente. Paulo Coelho é o exemplo mais famoso do segundo caso. Campeão de vendas, continua sendo rejeitado pela crítica jornalística e acadêmica. Os controladores do campo não podem provar que estão certos, pois não há mais "certo" em se tratando de gosto e de consumo cultural. Mas eles continuam detendo um poder cobiçado, inclusive por Paulo Coelho, o poder da legitimação. Publicar livros não faz um escritor. Faz, no máximo, um autor. O reconhecimento funciona como uma certificação. Cada campo é um cartório apto a conceder atestado de nascimento a quem aparecer. Atestados de óbito também são emitidos. O pior, contudo, parece ser a indiferença, a não atestação por recusa de receber o processo.

Porquê tanta necessidade de certificação numa época de crise de referenciais e de parâmetros em que todos os gostos são igualmente legítimos? Talvez seja esse o grande 
paradoxo da atualidade: quando tudo é possível, sem hierarquias absolutas, só o reconhecimento expresso de uma "autoridade" reconhecida pelo demandante de legitimação parece capaz de estabelecer um valor seguro. Guy Debord (1997, p. 12) sustentava que o "espetáculo não diz nada além de o que é bom aparece, o que aparece é bom". Trata-se de um critério circular de validação. Bom é o que funciona. Se funciona, é bom. Funciona como? Se encontra leitores, é bom. Se é bom, encontra leitores. O resto seria ruim. Salvo o que encontra uma crítica favorável, grau frequentemente mínimo de leitura e de vendas, sendo bom para esse tribunal de reputações e para a vaidade do autor e até mesmo para a sua carreira na medida em que prêmios podem lhe ser atribuídos.

Jean-François Lyotard (1986, p. 29), um dos grandes teóricos da pós-modernidade como espaço privilegiado da desconfiança em relação às "narrativas legitimadoras", destacava outro aspecto relevante:

numa sociedade em que a componente comunicacional torna-se cada dia mais evidente, simultaneamente como realidade e como problema, é certo que o aspecto da linguagem (langagier) adquire uma nova importância, que seria superficial reduzir à alternativa tradicional da palavra manipuladora ou da transmissão unilateral da mensagem, por um lado, ou da livre expressão ou do diálogo, por outro lado.

O que pode significar esse aspecto da linguagem nas estratégias de legitimação dentro de um campo? Numa perspectiva mais imediata, pode ser um "lance", no sentido de uma jogada argumentativa ou de visibilidade, de marketing, uma forma de subir na hierarquia do campo graças a dispositivos de valorização, passando de inexistente a dominado e de dominado a dominante. Numa vertente dialógica, porém, a situação é mais nobre: quem escreve normalmente o faz para ser lido. Ou seja, entra numa posição intersubjetiva, quer ser reconhecido e necessita para tanto, se não for praticante de algum solipsismo de esteta, desse aval externo para existir e dar sentido ao seu trabalho. Eis que se chega possivelmente a outro paradoxo: para ser reconhecido num campo é estrategicamente melhor seguir as suas regras ou desafiá-las? Deve-se escrever para o campo ou para si? Escrever para si pode ser a estratégia mais eficaz para ser reconhecido pelos outros?

Esse tema evidentemente não é novo. Mas pode ser explorado por ângulos diferentes. Ou arrancado da sua invisibilidade. $\mathrm{O}$ artista deve produzir os parâmetros de avaliação da sua obra. O preço a pagar é a rejeição pelo seu campo. O consolo obtido consiste em considerar-se como incompreendido. A história da literatura é rica em exemplos alentadores para quem ainda não alcançou a sonhada legitimação. No desespero sempre é possível citar o caso de Marcel Proust tendo sua obra-prima recusada por André Gide na editora Gallimard. A questão posta aqui, porém, vai além das tristezas e ressentimentos dos que ainda não foram condecorados por seus pares ou pelo público: como ousar em termos de narrativa quando se depende do reconhecimento de um campo, ou de vários, com suas regras e seus controladores? Uma possibilidade generosa é que o campo artístico tenha como norma de ouro a produção da novidade e de originalidade. Em outros termos, produção de diferença e descobrimento (Silva, 2017) como regra. 


\section{A NARRATIVA COMO APOSTA}

Resta saber o que pode ser considerado como novidade, originalidade, diferença e descobrimento? A diferença, como novidade radical, pode ser justamente o descobrimento: fazer algo emergir, destapar, revelar, desvelar, trazer à tona. Uma literatura de descobrimento pode ser aquela que produz diferença, logo originalidade, destapando por meios de técnicas de reportagem o que foi encoberto pela história e exige um olhar e uma narrativa transdisciplinares para se dar a ver na plenitude dos seus mistérios.

Não deixa de ser uma questão de método. Paul Feyerabend (1977, p. 229), defensor de uma "epistemologia libertária", provoca:

tendência dominante em discussões a propósito de metodologia é a de focalizar o problema do conhecimento sub specie aeternitatis, por assim dizer. Comparam-se enunciados uns com outros, esquecendo-Ihes a história e sem levar em conta a circunstância de poderem provir de estratos históricos diferentes. Indaga-se, por exemplo: dado certo conhecimento prévio, algumas condições iniciais, certos princípios básicos, várias observações reconhecidas - que conclusões será lícito retirar com respeito a uma hipótese recém-sugerida?

Que conclusões tirar de uma proposta de cruzamento de história, jornalismo e literatura com o objetivo de coletar dados e narrar o passado como uma grande reportagem sem que isso represente uma simplificação dos procedimentos dos historiadores nem "romancear" a suposta verdade histórica, mas, ao contrário, uma complexificação? Dadas as condições iniciais, expostas em tom de provocação, é permitido pensar que historiador, jornalista e escritor podem assumir essa condição de repórter cobrindo o passado. É questão de técnica e competência ou até mesmo, categoria escorregadia, de "talento". Mais do que tudo evidentemente se trata de uma atitude transdisciplinar.

Edgar Morin (1999, p. 164) vê na atitude transdisciplinar uma relação complexa entre explicação e compreensão:

a explicação é um processo abstrato de demonstrações logicamente realizadas, a partir de dados objetivos, em virtude de necessidades causais materiais ou formais e/ou em virtude de uma adequação a estruturas ou modelos. A compreensão move-se principalmente nas esferas do concreto, do analógico, da intuição global, do subjetivo. A explicação move-se principalmente nas esferas do abstrato, do lógico, do analítico, do objetivo. A compreensão compreende em função de transferências projetivas/identificatórias. A explicação explica em razão da pertinência lógico-empírica de suas demonstrações, enquanto compreender significa captar os significados existenciais de uma situação ou de um fenômeno.

Por que não supor que só se tem a ganhar na cobertura e na narração do passado com a aliança de sensibilidades e técnicas de jornalistas, historiadores e escritores capazes de dar conta, num mesmo movimento e até num mesmo pesquisador/autor, em 
profundidade e complexidade, dessa ponte entre explicação e compreensão, abstração e empatia, interpretação e descrição, reconstrução e verificação?

Paul Veyne (1998, p. 69), autor de um clássico sobre as armadilhas da narrativa histórica, já advertia com bom senso e elegância para quem não tivesse medo de aceitar sua constatação:

\begin{abstract}
uma vez que tal é a quintessência da explicação histórica, deve-se admitir que ela não merece tanto elogio e dificilmente se pode distingui-la do tipo de explicação que se pratica na vida cotidiana ou em qualquer romance onde essa vida é contada; ela é apenas a clareza que emana de uma narrativa suficientemente documentada; oferece-se por conta própria ao historiador na narração e não é uma operação distinta desta, assim como não o é para um romancista.
\end{abstract}

Nada se pode inventar na história e no jornalismo. Nem tudo, porém, se consegue provar, demonstrar, resolver, elucidar, explicar, descobrir, destapar, dar a ver. Os documentos dizem suas verdades, mas não contam necessariamente como foram produzidos. Cada escolha narrativa recorta o objeto a ser descrito jogando luz sobre uma parte e deixando outras nas sombras. O historiador e o jornalista interferem no fato a ser narrado pelo simples fato que usam "lentes" de observação. Não há olhar neutro. Eles selecionam o que contar, o que destacar, que perspectiva interpretativa adotar, escoIhem quando passar da explicação à compreensão e vice-versa, preenchem lacunas por dedução, dialogam com seus dados e com seus pares de investigação na busca de uma narrativa verossímil e convincente. Um arqueólogo, por exemplo, produz narrativas que exigem até mesmo intuição e imaginação. O grande historiador, portanto, pode ser um repórter que cobre o passado com a sensibilidade de um escritor e as técnicas dessas três áreas associadas numa atitude que derruba as cercas dos campos.

\title{
O TEMPO DA ESCRITA
}

Pensar o que se escreve obriga frequentemente a voltar sobre o que se costuma escrever. Cada autor tem seus temas obsessivos. Qual é o tempo da escrita? Modernidade? Pós-modernidade? Se for a pós-modernidade, como focá-la? a) Crise da ideia de verdade em ciências humanas e artes, ou crise das narrativas legitimadoras; b) fim da ilusão emancipacionista pela razão absoluta; c) ocaso da ideia de homem como sujeito racional, consciente e dominador da natureza numa caminhada inexorável para o bem, o belo e o verdadeiro; d) crepúsculo das utopias redentoras e do mito do progresso; e) fim das vanguardas iluminadoras e iluministas; f) niilismo irônico; g) humor cínico; h) ceticismo radical; i) relativismo epistemológico e estético; j) mescla de gêneros em arte; k) desconstrução; I) paródia; $m$ ) pastiche; $n$ ) retorno à narrativa sem retomada do realismo do século XIX nem assimilação pelo storyteller simplificador da indústria cultural; o) fim da ideia de representação; p) fim da separação entre alta e baixa cultura; q) ruptura com o estruturalismo (a pós-modernidade seria pós-estruturalista, mas o pós-estruturalismo 
nem sempre seria pós-moderno, sendo, muitas vezes, uma nova forma de militância ou a leitura norte-americana da pós-modernidade francesa); r) retorno da subjetividade (por exemplo no texto literário em oposição ao objetivismo do novo romance), equivalência entre significante e significado; s) retorno da frase limpa, em literatura, em oposição ao experimentalismo de linguagem moderno baseado na implosão ou explosão da palavra; t) intertextualidade, colagem, citação, mescla, saturação de imagens, barroquismo, cruzamento de estilos e épocas, ecletismo; u) concentrado narrativo de alta voltagem pela aceleração discursiva, simulação do "eu" como portador de um pseudouniversal; v) coloquialismo extremo e autoironia; w) retomada irônica da ficção de ideias sem defesa de tese ou militantismo; $x$ ) anarquismo epistemológico e estético; y) abordagem da cultura e da ideologia como imaginários ou como simulação de realidade, ou seja, como hiper-realidade, surrealismo, irrealismo; e z) a pós-verdade.

Cada item desse abecedário exigiria uma demonstração. A questão, porém, é outra, de contextualização. O que um tempo mostra? O que uma narrativa carrega do seu tempo? O que, por exemplo, um filme diz por trás do que ele mostra? O que um livro conta para além do que está escrito? O que uma obra revela sobre o que não diz explicitamente? O que a ironia desmascara? Tomemos um caso. O que diz este texto? Os algoritmos já dominam o mundo. Os seus porta-vozes garantem que eles são do bem. Não dirão isso manipulados pelos seus senhores algoritmos? Esses algoritmos, como os psicopatas, podem ser muito inteligentes. É uma inteligência opaca. Sem volta. Em breve, seremos todos escravos dos algoritmos. Como não teremos mais utilidade social, serviremos exclusivamente para satisfazer à perversidade dos algoritmos.

Uma primeira hipótese: revela o medo em relação ao avanço tecnológico. Uma segunda possibilidade: relativiza a força da técnica ao enfatizar uma tomada de distância pela subjetividade. Se o imaginário libera sentidos que as convenções de um tempo podem bloquear, o que nos diz uma obra - filme livro, crônica, uma letra de canção, uma biografia - sobre um tempo cujo alcance talvez ainda não tenha se encerrado? O intérprete não se vincula ao vivido como uma tela em branco. A lente e a tela encontram-se numa relação que pode ser acionada livremente. Hipótese metodológica: e se o imaginário for justamente o resultado da lente que provoca a tela com seu grau e é provocada pelo que vê gerando uma nova profusão de imagens? E se o imaginário for o mecanismo que conduz a mão na escolha do que escreverá? E se o imaginário for um agente secreto do seu tempo?

O espectador e o leitor não têm garantias contra o que veem e leem. Mas o que eles veem e leem? O sentido da recepção pode ser alterado se o espectador e o leitor encontrarem uma atmosfera de adesão ou de ruptura. Essa condição tende a surgir com a erosão do instituído, imagem congelada da emissão como proposta de olhar, que nunca deixa de ser recomposto em permanência pela ação reconstituinte da recepção. $A$ imagem oferecida como fotografia ou narrativa é um procedimento condicionante que opera como um perfume cujo aroma se esvai no contato com o receptor. O imaginário, como circuito que vai da imagem capturada ou construída à desmontagem ou remontagem de uma narrativa, é uma percepção social daquele que vê sobre aquilo que é 
projetado como a ser visto, a obra como reconstrução do vivido, uma rememoração, ou sua simulação, mediada pela sequência de imagens e revirada por quem sente, aquele que por sentir atribui sentido, o significado que só existe como relato de uma interpretação vivida.

Se o livro e o filme permitem uma reconstrução do vivido, o sentido atribuído interpela a imagem levando-a dizer o que mostra. Essa sequência banal exige um discurso. O que vem a ser esse discurso? O que dizem essas legendas? Pois, em certo sentido, é disso que se trata: legendar a imagem, comentar o texto, revelar o subtexto, dialogar com o encoberto. Para isso, impõe-se rever o conjunto de imagens como um todo estruturado que se apresenta como algo mais do que a soma das partes. Essa caminhada do fim para o começo estabelece uma trajetória pela qual o intérprete se interpreta. $\mathrm{Na}$ interpretação, encontram-se o olhar capturado e a ação de capturar. Essa relação de leitura pode ser uma operação consciente ou inconsciente de esclarecimento mesmo que o imaginário do cinema e do livro se alimentem da atmosfera do escuro. Tudo pode ficar mais claro na escuridão interrompida pelo holofote da tela ou pela transparência da página coberta por signos. A interpretação como método de reconstrução obriga a dizer o que se viu e leu, o que só se pode colocar à luz do dia depois, ao final da recepção. O termo projeção, em se tratando de filmes, talvez ainda diga mais: exibição do projeto, orientação do olhar, entrega da proposta. Todo filme fornece lentes para que o espectador o compreenda. Todo livro sugere sua leitura. O espectador e o leitor, porém, carregam no bolso as próprias lentes, que o transformam em intérprete, aquele que vê e remonta a narrativa ao ler.

Aquilo que descongela a imagem, como ato interpretativo ou reconstrução de um projeto, é a chave da interpretação como percurso. Na passagem da imagem ao imaginário edifica-se uma estrutura passível de decupagem. Aquilo, ou aquele, que decupa, lê, decompõe, recompõe, reinventa, narra e propõe. O espectador - todo leitor é um espectador - convertido em intérprete, liberta-se do projeto do autor e projeta-se na obra como um usurpador, um traidor, um montador, um roteirista, um narrador, um autor. $A$ interpretação desconfigura e reconfigura. Toda interpretação é um ato de infidelidade assumida e necessária. O intérprete, esse leitor que vê e revê, abala o fundamento narrativo.

O que se vê por meio de imagens que evocam um mundo de sons? O que se vê através de signos que remontam um universo ausente? $O$ imaginário pode ser ouvido, visto e lido como uma composição. A nota que transborda e ecoa como uma trilha que ampara o vivido, a musicalidade que estava no trajeto como projeção do ser. O trabalho de decupagem (leitura de reconfiguração) do imaginário nunca se livra dessa vibração que explora a sonoridade da metáfora como imagem em imagem. Interpretar significa fazer vibrar os sentidos silenciados, ofertar o ouvido, iluminar, dialogar com a imagem, explorar o subjacente, provocar o excedente, revisar ou escolher as legendas, provocar imagem com texto até a produção de um contexto, um agregado de imagens sobre imagens. Aquele que interpreta, imagina, revela-se, desvela-se, exibe-se para si e para que o interpretará, diz o que viu do ponto de vista da reflexão, que é sempre espelho distorcido. Ver e ler é dar-se a ver sob a luz da compreensão. Desnudar-se pela tela. 
A interpretação é um processo de aproximações sucessivas e permanentes. A primeira olhada é exploratória e diletante. Pode ser ingênua ou precavida, informada ou conformada. Enfrenta o solo lavrado, assinado pela lavra do autor, recoberto pela mata simbólica do narrado. Interpretar não é recolher a imagem madura, mas procurar as raízes do que foi inseminado. Aquele que interpreta e aquilo que é interpretado se descobrem simultaneamente. $O$ intérprete sugere uma narrativa para o interpretado. Essa sugestão não é verdadeira nem falsa. É um desvelamento, um encontro de perspectivas, um diálogo em ato. Essa provocação projeta evocações que provocam novas operações cognitivas. Interpretar tira as imagens da inércia finalizada.

A interpretação do imaginário talvez requeira uma hermenêutica de superfície, pois a camada que cobre a imagem, antes da sua transfiguração em imaginário, permanece ao alcance da mão. Interpretar é retirar essa tênue cobertura. Escavar e espanar, ver, ouvir e contar, sentir, vibrar e narrar. A interpretação que encontra adesão se legitima como leitura pertinente. $\mathrm{Na}$ interpretação sempre há uma perda, a perda desse discurso original ou originário da autoria.

O intérprete invade o palco, entra na tela, na página, encena, apossa-se do cenário, reorganiza a cena, narra o que está vendo e interpela o acontecimento como novo ator, narrador e autor. Mas não o faz livremente como numa ficção autoral. A interpretação acompanha um roteiro ainda que para dele divergir ou tentar negá-lo. A referência fica à espreita. $O$ ato dialógico da interpretação não pode prescindir do encontro das partes. É como se a cada momento marcante fosse necessário voltar atrás para conferir uma imagem, um parágrafo, um símbolo, um efeito, precisamente uma marca, a referência consumada.

A interpretação é compreensiva e relativista. Põe em relação e pratica a empatia. Explora a impossibilidade de reduzir a imagem à razão fechada. Os procedimentos abstratos da lógica pouco podem diante da experiência que condiciona o olhar. A compreensão não escapa da fascinação. A interpretação dialoga com a explicação e a compreensão em plano aberto, em página livre, texto em construção. A pós-modernidade colocou sob suspeita velhas verdades que se afirmavam como universais sem a prova da prova dessa ambição desmesurada. Mostrou-se o quanto há de ficção e de construção em cada relato. Paradoxalmente, nesta época de desconfiança em relação à realidade do real, os leitores apreciam como nunca narrativas que possam se apresentar como "verdadeiras": depoimentos, relatos de viagem e biografias. É preciso que o autor convença o leitor de que ele esteve lá. Narrar é viver.

Toda definição é tomada como uma narrativa e como tal passível de ironia e de relativização. Alguns exemplos à guisa de provocação. Ideologia: lente que define aquilo que é observado. Óculos que conforma, deforma ou reforma a narrativa podendo até coincidir com o descrito. Imaginário social: ficção coletiva compartilhada como realidade objetiva. Política: domesticação do poder ou poder de domesticação. Ciência política: a opinião de cada um nas regras da academia. Economia: ciência com poder de previsão tão eficaz quanto o da astrologia. Impeachment: o golpe na visão dos beneficiados. Golpe: impeachment que não convenceu a todos. Democracia: sistema político em que 
cada voto pode ser precificado antes ou depois da eleição. Realidade: autoficção sustentada por pessoas com elevada autoestima.

Outras possibilidades. Direito: ideologia pela qual certas pessoas podem dizer o que é a lei. Comunismo: o pior modo de organização socioeconômica junto com o capitalismo. Mídia: sistema de manipulação da opinião para que ela se torne pública. Opinião pública: visão de mundo de origem privada, autoria desconhecida e consequências previsíveis. Político profissional: pessoa que desistiu da sua profissão para viver como amador. Profissional de marketing: especialista em deformar a realidade de preferência sem mentir, mas também sem falar a verdade. Youtubers: famosos que a maioria ainda desconhece. Inteligência artificial: sabedoria natural das máquinas. Best-seller: obra lida por quem nunca abre um livro. Pós-trabalho: nome que se dará a um mundo em que todos estarão desempregados. Pós-humano: evolução do homem para a sua condição totalmente animal.

Em tempos de aceitação geral de que as ciências, não só as humanas, mas certamente em especial elas, são probabilísticas, trabalhando com hipóteses que sempre devem ser expostas a refutações sucessivas, todo relato, ou mesmo todo relatório de pesquisa, é narrativa, o que apaga a suposta nitidez da fronteira com o ensaio. Nesse sentido, tudo é experimentação, possibilidade ou aposta.

\section{CONCLUSÃo PROVISÓRIA}

O foco deste texto não foi a falta de legitimidade de quem por ventura pratica o cruzamento complexo entre jornalismo, história e literatura. Essa foi apenas uma questão secundária ou derivada. O ponto principal desta reflexão esteve concentrado na ideia de pensar o historiador como um repórter que cobre o passado recorrendo a ferramentas narrativas de escritor para a divulgação dos seus resultados. Dito de outra maneira, retomando um termo polissêmico, o historiador é um cronista que interpreta o passado. $O$ termo cronista, contudo, foi ganhando cada vez mais uma acepção literária, a literatura no jornalismo. A crônica explora profundamente a compreensão, a empatia, a descrição, a narração, a reconstrução.

Do ponto de vista prático o que pode um cronista/repórter do passado ousar na apresentação do seu material para, sem perder o rigor, dar-lhe uma forma capaz de ser lida fora do seu campo de atuação, onde, muitas vezes, a leitura nem acontece, servindo o "relatório" apenas como comprovação de que o trabalho foi realizado? Pode eliminar o jargão legitimador da área? Pode ser claro sem correr o risco de ser acusado de superficialidade? Pode valorizar mais a pesquisa empírica do que a teoria? Pode privilegiar o livro ao artigo? Pode tirar a bibliografia do final do livro e diluí-la ao longo do texto para quebrar a formalidade do relato? Há algum espaço para a ousadia formal na rigidez dos campos regidos pela academia? Qual campo é mais aberto a algum tipo de experimentação: comunicação, história ou letras? Ou nenhum deles permite qualquer infração ao regulamento?

Uma leitura menos atenta poderá imaginar que este texto reflete uma insatisfação com as normas exigidas pelo discurso científico. Trata-se, no entanto, de uma análise em movimento sobre as condições de possibilidade de alargamento das linhas 
demarcatórias dos campos em termos de recursos de pesquisa e de dispositivos de narração. Não houve intenção de atingir suscetibilidades de historiadores nem de hiperdimensionar o papel dos jornalistas. Tampouco se quis reduzir tudo a ficção. Em certo sentido, caso fosse necessário concluir estranhamente sob a forma de uma pergunta de síntese, seria esta: a narratividade nas ciências humanas ou nas ciências sociais aplicadas têm espaço para a escrita criativa para além da esfera literária?

Não é difícil imaginar a contrariedade que tal proposição é capaz de gerar. A resposta padrão certamente deve ser: ciência é ciência e tem seus protocolos de pesquisa e de apresentação de resultados. A característica da ciência, nessa perspectiva específica, não seria fazer, mas pensar o fazer. Como, porém, ecoando a complexidade moriniana, pensar o fazer do fazer, ou seja, os aspectos que envolvem o fazer que pensa outra fazer? O senso estratégico do leitor de Pierre Bourdieu manda avaliar a força do analista dentro do seu campo. Se for dominado, melhor seguir o regulamento. Se for dominante talvez caiba uma ousadia. Mas isso não afetará a sua posição? Não acarretará uma asfixia de acordo com o alerta de Lyotard?

Outro aspecto considerado foi o lugar desse questionamento: fóruns políticos e administrativos ou textos acadêmicos? Sociologia da ciência ou epistemologia? Se cada campo tem suas regras, como constituir regras transdisciplinares, com base na ideia de um conhecimento conjuntivo, sem necessariamente se isolar numa espécie de gueto mantido sob controle e bem cercado para evitar que contamine os demais? Na falta de um fecho de ouro, serve este: há espaço para a criatividade narrativa na divulgação de resultados científicos? /

\section{REFERÊNCIAS}

Bourdieu, P. (1997). Sobre a televisão. Rio de Janeiro: Jorge Zahar.

Bourdieu, P. (1992). Les règles de l'art-genèse et structure du champ littéraire. Paris: Seuil.

Debord, G. (1997). A sociedade do espetáculo. Rio de Janeiro: Contraponto.

Feyerabend, P. (1977). Contra o método. Rio de Janeiro: Francisco Alves.

Lyotard, J.-F. (1986). O Pós-moderno. Rio de Janeiro: José Olympio.

Morin, E. (1999). O método 3: o conhecimento do conhecimento. Porto Alegre: Sulina.

Silva, J. M. da. (2017). Diferença e descobrimento. O que é o imaginário. A hipótese do excedente de significação. Porto Alegre: Sulina.

Veyne, P. (1998). Como se escreve a história. Brasília: UNB.

\section{NOTA BIOGRÁFICA}

Juremir Machado da Silva, doutor em Sociologia pela Sorbonne, Paris V, escritor, historiador, jornalista, radialista e tradutor, é pesquisador $1 \mathrm{~B}$ do $\mathrm{CNPq}$, coordenador do 
Programa de Pós-Graduação em Comunicação da PUCRS e autor, entre outros livros, de A miséria do jornalismo brasileiro (Petrópolis, Vozes, 2000), As Tecnologias do imaginário (Porto Alegre, Sulina, 2003), O que pesquisar quer dizer (Porto Alegre: Sulina, 2010), História regional da infâmia - o destino dos negros farrapos e outras iniquidades brasileiras, ou como se produzem os imaginários (Porto Alegre: L\&PM, 2010), Vozes da Legalidade: política e imaginário na era do rádio (Porto Alegre, Sulina, 2011), Um escritor no fim do mundo: viagem com Michel Houellebecq à Patagônia (Rio de Janeiro: Record, 2011) e dos romances Getúlio (Rio de Janeiro, Record, 2004), Solo (Rio de Janeiro: Record, 2008) e 1930: águas da revolução (Rio de Janeiro: Record, 2010); A sociedade Midiocre - passagem ao hiperespetacular - o fim do direito autoral, do livro e da escrita. Porto Alegre; Sulina, 2012; Jango, a vida e a morte no exílio: (como foram construídos, com ajuda da mídia, o imaginário favorável ao golpe e as narrativas sobre as suspeitas de assassinato do presidente deposto em 1964). Porto Alegre: L\&PM, 2013; 1964: golpe midiático-civil-militar. Porto Alegre: Sulina, 2014; Correio do Povo: a primeira semana de um jornal centenário. Porto Alegre: Sulina, 2015; Corruptos de estimação e outros textos sobre o golpe hiper-real. Porto Alegre: Sulina, 2016. Diferença e repetição: o que é o imaginário. Porto Alegre: Sulina, 2017. Raízes do conservadorismo brasileiro: a abolição na imprensa e no imaginário social. Rio de Janeiro: Civilização Brasileira, 2017.

ORCID: https://orcid.org/0000-0001-8105-5596

Email: Juremir@pucrs.br

Morada: PUCRS, Av. Ipiranga, 6681 - Prédio 7 - Partenon - Porto Alegre/RS

CEP: $90619-900$

* Submetido: 03.05.2018

* Aceite: 12.07.2018 